\title{
El problema de la responsabilidad del acreedor moroso en el nuevo Código Civil y Comercial argentino*
}

\author{
Manuel Grasso ${ }^{a}$
}

\begin{abstract}
Resumen: El Código Civil y Comercial argentino carece de una norma expresa que imponga al acreedor moroso el deber de reembolsar los gastos y resarcir los daños provocados por su mora. Con todo, la doctrina reconoce ese deber sin dar muchas explicaciones. Este artículo emplea la metodología propia de la dogmática jurídica y se propone abordar el problema a partir de las fuentes legislativas y doctrinarias argentinas y revisar algunos modelos normativos europeos y latinoamericanos. Tras examinar ese material, se intenta construir una solución basada en conceptos y reglas presentes en el propio Código argentino. En particular, la definición normativa de obligación, las exigencias que derivan de la buena fe, el empleo útil y el enriquecimiento sin causa permiten componer una solución articulada capaz de dar respuesta al problema de las consecuencias negativas sufridas por el deudor dispuesto a cumplir, pero imposibilitado de liberarse por razones que son atribuibles a la esfera propia del acreedor, culpable o no.
\end{abstract}

Palavras-chave: mora del acreedor; gastos y daños; buena fe; empleo útil; nuevo Código Civil y Comercial argentino; derecho comparado

Recibido: 26 de septiembre de 2019 Aceptado: 22 de mayo de 2020

Disponible en línea: día, mes y año.

Cómo citar: Grasso, M. (2020). El problema de la responsabilidad del acreedor moroso en el nuevo Código Civil y Comercial argentino. Prolegómenos, 23(46). 133-148. DOI: https://doi.org/10.18359/ prole.3663

* Artículo de investigación.

a Maestro y Doctor en "Sistema jurídico Romanístico, unificación del derecho y derecho de la integración" por la Università degli Studi di Roma 'Tor Vergata' (Italia); exbecario del Programa de Postdoctorado del Consejo Nacional de Investigaciones Científicas y Técnicas (Argentina), Profesor de Derecho Romano y Derecho Civil en la Facultad de Derecho de la Universidad de los Andes. Santiago, Chile. Correo: mgrasso@uandes.cl 


\title{
The symbolic importance of Law and the foundations of the Utrumque Ius
}

\begin{abstract}
The Argentine Civil and Commercial Code lacks an express norm imposing on the delinquent creditors the obligation to reimburse the expenses and compensate the damages caused by their default. However, the doctrine recognizes that obligation without giving many explanations. This article uses the methodology of legal dogmatics and aims at addressing the problem using Argentine legislative and doctrinal sources and reviewing some European and Latin American regulatory models. After examining this material, an attempt is made to build a solution based on concepts and rules present in the Argentine Code itself. In particular, the normative definition of obligation, the requirements that derive from good faith, useful employment and enrichment without cause which make possible to create an articulated solution that can respond to the problem of the negative consequences suffered by the debtor willing to comply, but unable to free himself for reasons attributable to the creditor's own realm, guilty or not.
\end{abstract}

Keywords: creditor default; expenses and damages; good faith; useful employment; new Argentine Civil and Commercial Code; comparative law

\section{A importância simbólica do Direito e os fundamentos do jus utrumque}

Resume: O Código Civil e Comercial argentino carece de uma lei expressa que imponha ao credor moroso o dever de reembolsar as despesas e ressarcir os danos provocados por sua mora. Contudo, a doutrina reconhece esse dever sem dar muitas explicações. Este artigo utiliza a metodologia própria da dogmática jurídica e se propõe a abordar o problema a partir das fontes legislativas e doutrinárias argentinas, e verificar alguns modelos regulatórios europeus e latino-americanos. Após examinar esse material, tenta-se construir uma solução baseada em conceitos e regras presentes no próprio Código argentino. Em específico, a definição normativa de obrigação, as exigências que derivam da boa-fé, o emprego útil e o enriquecimento sem causa permitem compor uma solução articulada capaz de dar resposta ao problema das consequências negativas sofridas pelo devedor disposto a cumprir, mas impossibilitado de se liberar por razões que são atribuídas à esfera própria do credor, culpado ou não.

Palavras-chave: mora do credor; despesas e danos; boa-fé; emprego útil; novo Código Civil e Comercial argentino; direito comparado 


\section{Introducción}

La obligación es un esquema jurídico complejo y versátil, capaz de asumir múltiples y variadas articulaciones. Sin embargo, es posible reconocerle una estructura básica, primordial: sobre el deudor pesa el deber de realizar una determinada prestación con valor económico, al acreedor beneficia la utilidad que reporta el comportamiento debido.

Cuando el deudor no ejecuta la prestación y se verifican - además- determinadas condiciones, se dice que cae en mora, y entonces surge el deber de resarcir los daños que el incumplimiento produjo.

Menos evidente, menos natural, quizás menos frecuente, pero de ninguna manera menos importante, parece ser aquella situación en la cual es el acreedor quien retrasa o frustra definitivamente la prestación que es objeto de su derecho de crédito. La institución jurídica "mora del acreedor" se compone de normas y principios que regulan dos órdenes de problemas: a) concepto y requisitos de configuración y b) identificación y regulación de los efectos jurídicos. Entre los efectos jurídicos que se le suele atribuir, se encuentra el surgimiento del deber a cargo del acreedor moroso de resarcir los daños que el deudor hubiere padecido a causa de la mora.

Existencia, fundamento y extensión son los tres problemas que, conectados por una interrelación, se asocian a ese efecto de la mora creditoris. En efecto, se afirma la existencia del deber en virtud de una norma expresa que lo consagra; o porque puede derivarse de una regla general que le sirve de fundamento, aun sin una norma expresa que lo consagre, o bien se niega la existencia del deber cuando no es posible identificar un fundamento. Por otra parte, y siempre que se suponga la existencia del deber, surge automáticamente el tercer problema: el de su extensión, es decir, ¿a qué y en qué medida queda eventualmente obligado el acreedor moroso? La respuesta se halla, también aquí, en interrelación con el fundamento del deber. En hipótesis, hay diversos grados de extensión de las consecuencias negativas que habrá de soportar el acreedor moroso a causa de su mora: ¿debe reintegrar al deudor exclusivamente los gastos de custodia y conservación de la cosa debida?; ¿debe cubrir el mayor valor que la prestación a cargo del deudor ha alcanzado a causa de su mora?; ¿debe acaso también resarcir cualquier daño "extrínseco", esto es, no asociado directamente a la prestación, pero ocasionados por el rechazo injustificado de la oferta de cumplimiento?

El presente estudio aborda los tres problemas en relación con el derecho argentino vigente. El Código Civil y Comercial argentino vigente (CCCARG, 2014) ha dado relativa autonomía conceptual a la figura de la mora del acreedor (Alferillo, 2016a). Sin embargo, ha dejado algunos problemas sin resolver, entre ellos se encuentra precisamente- el de las consecuencias negativas que esa mora puede eventualmente producir. Pese a esta falta de solución legal expresa, la doctrina no ha advertido ningún inconveniente o insuficiencia. Nos proponemos evidenciar esa deficiencia legislativa, advertir la consiguiente necesidad de reflexión a nivel dogmático y, por último, enseñar una propuesta de una solución ${ }^{1}$. Como rendimiento práctico, se espera que esta investigación aproxime algunas ideas destinadas a enriquecer la discusión sobre las consecuencias jurídicas negativas de la mora creditoris, la existencia, fundamento y extensión de la responsabilidad del acreedor moroso; además, la propuesta de solución podrá guiar decisiones judiciales o bien estimular críticas e impulsar propuestas superadoras ${ }^{2}$.

1 La dogmática jurídica — después de todo—es una disciplina que persigue diversos objetivos mediante el desarrollo de una serie de tareas a) analizar el derecho vigente a la luz de sus fuentes legales, jurisprudenciales y doctrinarias; b) proponer luego un marco conceptual que permita discernir el derecho como un ordenamiento comprensible y relativamente coherente, poniendo sobre aviso de las inconsistencias lógicas y de sus compromisos valorativos, y c) proponer innovaciones doctrinarias allí donde se descubran vacíos, contradicciones o aberraciones lógicas o valorativas (Barros, 2008, p. 317).

2 El desafío actual de la ciencia jurídica argentina pasa por, según la propuesta de López-Mesa (2016), "interpretar, integrar y explicitar ese texto normativo del mejor modo posible, para darle por vía hermenéutica la lógica, coherencia y profundidad de la que carece en origen” (p. 59). 
El camino para aportar una propuesta de solución se compone de tres etapas. Primero, nos dedicaremos a describir el estado de la cuestión en el derecho argentino: revisaremos las normas del Código Civil y Comercial aprobado en 2014 a fin de confirmar que no hay reglas que expresamente permitan resolver algunos problemas asociados a la mora creditoris, marcaremos asimismo el contraste con los textos legislativos precedentes (Código derogado y sucesivos Proyectos de reforma integral) que expresamente se ocupaban de algunas cuestiones y concluiremos el apartado con un repaso de la interpretación doctrinaria bajo el imperio de ambos regímenes. Segundo, examinaremos algunos modelos legislativos presentes en los ordenamientos jurídicos nacionales y supranacionales contemporáneos, europeos y latinoamericanos. Tercero, tras recuperar y examinar en conjunto el material obtenido durante de la investigación, el trabajo finalizará con algunas conclusiones que plasman una propuesta de solución al problema.

\section{Responsabilidad del acreedor moroso en el derecho argentino}

El ordenamiento jurídico argentino experimentó una transformación integral a nivel legislativo en el año $2014^{3}$. En relación con el régimen anterior, el nuevo ha legislado algunos aspectos (muy pocos) de la mora del acreedor, pero ha perdido la oportunidad de regular sobre quién y en qué medida pesan las desventajas económicas (gastos afrontados $y$, en general, daños padecidos) que ha experimentado el deudor a causa del retraso del acreedor en recibir la prestación.

La omisión nos obliga a reflexionar sobre el tema en perspectiva diacrónica: no basta con describir el estatuto normativo que se le da a esa

3 El 1. ${ }^{\circ}$ de octubre de 2014 se aprobó (Ley 26994) el Código civil y comercial de la Nación Argentina que entró en vigor el 1. de agosto de 2015. Este texto normativo derogó el Código civil de la República Argentina redactado por Dalmacio Vélez Sársfield, aprobado en 1869 y vigente desde 1871. Bajo el imperio del Código derogado se elaboraron distintos Proyectos de reforma integral del derecho privado argentino: ninguno de estos Proyectos había logrado entrar en vigor. institución jurídica en el Código vigente, sino que es imprescindible entender cómo estaba regulada en el Código derogado y en los Proyectos de reforma anteriores al que finalmente tuvo aprobación y reconstruir la elaboración doctrinaria en tiempos del régimen derogado y en la actualidad.

\section{La mora del acreedor en el Código Civil y Comercial (2014)}

El nuevo texto legal argentino parece acoger la teoría unitaria de la mora ${ }^{4}$ :

Mora del deudor. Principio. Mora automática. Mora del acreedor. La mora del deudor se produce por el solo transcurso del tiempo fijado para el cumplimiento de la obligación. / El acreedor incurre en mora si el deudor le efectúa una oferta de pago de conformidad con el artículo 867 y se rehúsa injustificadamente a recibirlo (CCCARG, 2014, art. 886).

La redacción del artículo ${ }^{5}$ sugiere que la mora del acreedor se espeja en la del deudor, la que asume carácter paradigmático. En otras palabras: la mora del acreedor sería la hermana menor de una mora paradigmática que es la del deudor ${ }^{6}$.

4 Para un desarrollo de esta teoría y su contraria, es decir, aquella que concibe la mora de acreedor como figura distinta e independiente de la mora del deudor, véase (Pizarro y Vallespinos, 1999, pp. 265-266).

5 El precepto inicia la Segunda Sección sobre la "Mora”, ubicada en el Capítulo 4 relativo al "Pago", incluido en el Título I, intitulado "Obligaciones en general” del Libro Tercero, que trata sobre los “Derechos personales".

6 De hecho, el resto de los artículos que integran la Sección del artículo citado (cCCARG, 2014, arts. 887 y 888) contienen dispositivos legales que regulan aspectos de la mora del deudor, como lo demuestra claramente la referencia al "deudor" que contiene el artículo 888: "Para eximirse de las consecuencias jurídicas derivadas de la mora, el deudor debe probar que no le es imputable, cualquiera sea el lugar de pago de la obligación”. 
Además de la definición del art. 886, solo hay otras tres referencias a la mora del acreedor en el Código argentino. La más importante es la del art. 904 inc. a), que la enumera entre los requisitos para la procedencia del pago por consignación judicial7.

En definitiva, el marco normativo argentino de la mora creditoris es más bien modesto. El Código vigente se limita a definir la mora del acreedor; se regula de manera detallada su principal efecto, es decir, habilitar el pago por consignación, y hay unas pocas normas desparramadas aquí y allá sin demasiada relevancia general. No hay, pues, una solución expresa al problema de los gastos y de los eventuales daños derivados del rechazo injustificado por parte del acreedor de una real y correcta oferta de pago realizada por el deudor.

Sin embargo, esta constatación no ha generado ninguna inquietud entre los autores nacionales. Compagnucci de Caso (2017) - para citar a un autor que se ha ocupado especialmente del temaenumera los efectos de la mora acreedor y coloca en primerísimo lugar la obligación del acreedor de pagar los daños causados, describiendo este efecto del siguiente modo: "en cuanto al pago de las indemnizaciones que correspondan, es producto del incumplimiento a deberes contractuales y de la suma de los elementos que hacen a la responsabilidad civil. Cuestión que no exige mayores explicaciones" (p. 270).

Nuestro punto de partida es precisamente opuesto al expresado por este autor: la cuestión necesita ser explicada y exige una demostración. Para empezar, conviene visualizar el régimen derogado.

7 Las dos restantes menciones carecen de importancia a nivel general (cccarg, 2014, arts. 819 y 1268).

\section{El Código Civil derogado (1869) y los Proyectos de reforma al derecho privado argentino}

El texto derogado (CCARG, 1869) no contenía normas generales relativas a la mora del acreedor (Wayar, 2000, p. 364; Llambías y Raffo-Benegas, 2012, p. 133$)^{8}$. Aun así, la doctrina enunciaba, entre los efectos de la mora del acreedor, la responsabilidad por los daños y perjuicios causados. Esa interpretación encontraba sustento en normas del propio Código. De hecho, pese a que no existía una consagración expresa a nivel general, había dos normas en materia de compraventa que habilitaban su extensión en términos de regla general:

si el comprador de una cosa mueble deja de recibirla, el vendedor, después de constituido en mora, tiene derecho a cobrarle los costos de la conservación y las pérdidas e intereses; y puede hacerse autorizar por el juez para depositar la cosa vendida en un lugar determinado, y demandar el pago del precio o bien la resolución de la venta (CCARG, 1869, art. 1430).

Si la venta hubiese sido de cosa inmueble y el vendedor hubiese recibido el todo o parte del precio, o si la venta se hubiese hecho a crédito y no estuviere vencido el plazo para el pago, y el comprador se negase a recibir el inmueble, el vendedor tiene derecho a pedirle los costos de la conservación e indemnización de perjuicios y a poner la cosa en depósito judicial por cuenta y riesgo del comprador (CCARG, 1869, art. 1431).

Además de los costos de conservación, estos dispositivos legales hacían responsable al acreedor por las "pérdidas e intereses" (art. 1430) y la "indemnización de perjuicios" (art. 1431).

8 El codificador solo se había referido a la figura en la nota al art. 509 cCARG, 1869: "El acreedor se encuentra en mora toda vez que, por un hecho o por una omisión culpable, hace imposible o impide la ejecución de la obligación, por ejemplo, rehusando aceptar la prestación debida en el lugar y tiempo oportuno, no encontrándose en el lugar convenido para le ejecución o rehusando concurrir a los actos indispensables para la ejecución, como la medida o el peso de los objetos que se deban entregar, o la liquidación de un crédito no líquido”. 
Por otra parte, los Proyectos de reforma al derecho privado argentino (1926-1998) regulaban expresamente el problema de la responsabilidad del acreedor moroso.

Así, entre otros efectos de la mora crediticia, el Anteproyecto de 1954 enunciaba de manera categórica lo siguiente: "Si el acreedor fuere constituido en mora [...] responderá por los daños y perjuicios que su mora causare al deudor" (art. 982 citado en Moisset de Espanés, s. f., p. 26). No menos categórica era la regulación propuesta en el Proyecto de 1993 de la Comisión Federal:

el acreedor incurre en mora y es responsable frente al deudor, cuando se niega en forma injustificada a aceptar el pago o a prestar la cooperación indispensable para que éste se efectúe; o cuando interpelado al efecto, no realizare los hechos que le incumben para que se verifique el referido pago (art. 507 Moisset de Espanés, s. f., 28 nt. 56).

El Proyecto de 1998 proponía este texto:

el acreedor incurre en mora si el deudor le efectúa una oferta real de pago y se rehúsa injustificadamente a recibirlo. Se aplican en lo pertinente, las disposiciones relativas a la mora del deudor, así como lo establecido en el artículo 677 (art. 1598) ${ }^{10}$.

En suma, recogiendo lo más importante del devenir normativo, podríamos trazar el siguiente esquema: regla específica, aunque expansible, en el Código derogado; prevalencia de una regulación expresa con alcance general en los Proyectos de reforma al derecho privado argentino; ausencia de norma expresa en el Código vigente.

9 El Anteproyecto Bibiloni (presentado en 1929) establecía que: "El deudor, en caso de mora del acreedor, podrá pedir una indemnización por el aumento de los gastos que ha debido hacer por razón del requerimiento infructuoso, y por la detención y conservación de la cosa adeudada (art. 1190)" (citado en Moisset de Espanés, s.f., 22 nt. 49). El Proyecto de 1936 consagraba un artículo a la enunciación de los efectos de la mora del acreedor, entre los que enumera que: "El deudor tendrá derecho a que se le indemnicen los gastos de conservación, o guarda, así como los motivados por el requerimiento infructuoso" (art. 710 inc. $4 .^{\circ}$ citado en Moisset de Espanés, s.f., 24 nt. 52).

\section{La doctrinal nacional}

Es necesario retomar el interrogante que guía esta investigación: ¿debe hacerse cargo el acreedor moroso de los gastos que provoca su rechazo injustificado?, ¿nace de la mora la obligación de acreedor de resarcir los eventuales daños y perjuicios?

Bajo el imperio del régimen derogado, la posición mayoritaria de los autores era afirmativa ${ }^{11}$. Según Pizarro y Vallespinos (1999):

10 Comisión Honoraria designada por decreto del Poder Ejecutivo Nacional N. ${ }^{\circ} 685 / 95,1998$. Dos son los aspectos interesantes de este último proyecto. En primer lugar, la remisión al artículo 677 permite elevar a grado de "incumplimiento" el rechazo injustificado, ya que ese dispositivo establece que "[t]anto el deudor como el acreedor deben cooperar, de buena fe, para que el interés de éste sea satisfecho mediante la prestación”. En segundo lugar, desde el punto de vista sistemático, el Proyecto regulaba la mora, en sus dos variantes, debitoris y creditoris, en la parte relativa a "otras fuentes de las obligaciones" bajo la rúbrica "responsabilidad civil”. En los fundamentos del Proyecto se subraya la introducción de "un texto atinente a la mora del acreedor, remitiendo a las normas de la mora del deudor", propuesta que encontraba un antecedente en la Recomendación N. ${ }^{\circ} 6$ Cuarto Congreso Nacional de Derecho Civil (Córdoba, 1969). También nos informa Moisset de Espanés (s. f.) que la decisión había sido criticada por considerar que el efecto principal de la mora del acreedor: "es trasladar los riesgos de pérdida o imposibilidad de la prestación, que dejan de pesar sobre el deudor, y no siempre este retardo del acreedor en recibir o prestar su colaboración ocasionan daños al deudor; es decir, hay hipótesis de mora crediticia que no alcanzan a ser fuente de obligaciones autónomas” (p. 30).

11 Sin embargo, en contra están Borda y Borda (2012), quienes enuncian como efecto de la mora del a "pagar al deudor los mayores gastos que haya debido hacer éste con motivo de la mora; por ejemplo, los gastos de conservación y cuidado de la cosa, los honorarios y gastos del juicio de conservación” (p. 89), sin integrar en el contenido del deber posibles daños ulteriores sufridos por el deudor. 
en nuestro sistema los efectos de la mora del acreedor coinciden, en lo sustancial, con los que provoca la mora del deudor [...]. En consecuencia, quien se encuentra en mora creditoris responde por los daños y perjuicios causados al deudor en razón de la falta de cooperación ( $v$. gr. gastos de conservación de la cosa, de traslado, de ofrecimiento, frustración de ganancias, etcétera) (pp. 286-287) ${ }^{12}$.

Salvat y Galli (1952) consideraban que la mora del acreedor (constitución, efectos y cesación) se regía por las mismas reglas que la del deudor, dado que el silencio de la ley impone aplicar leyes análogas, que la culpa era un elemento constitutivo de la mora creditoris y, entre los efectos "deducidos de los que el Código atribuye a la mora del deudor", enunciaban en primer lugar el siguiente: "el acreedor debe resarcir al deudor todos los daños que le haya producido su retardo en recibir la prestación, como ser los gastos de oferta y los ulteriores de la custodia" (p. 122).

Para ejemplificar qué daños debería resarcir el acreedor, Llambías y Raffo-Benegas (2012) aludían a los gastos efectuados al ofertar el pago y derivados de la custodia de la cosa debida, aclarando que:

[...] para que el acreedor sea responsable de la situación de mora en que estuviera incurso, es necesario que ella le sea imputable, pues sin imputabilidad no hay responsabilidad [pues] si no obstante la situación de mora del acreedor, ella no le fuese imputable, quedaría fuera de la cuestión su responsabilidad los daños y perjuicios que sufriere el deudor por la falta de recepción del pago, $v$. gr., si el acreedor, a raíz de un accidente de tránsito, sufriera una prolongada privación de discernimiento o si fuese un insano que careciera de representante (pp. 134-135).

Como contrapartida, el deudor no quedaba desprotegido frente a estas situaciones, pues "siempre le será posible recurrir a la consignación en pago que lo libera de la obligación" (Llambías y Raffo-Bennegas, 2012, pp. 134-135).

12 En este sentido, Compagnucci de Caso (1982, p. 999) e, incluso después de la entrada en vigor del nuevo Código, Alferillo (2016a, p. 942).
Según Wayar (2000), todo "habrá de regirse por los principios y reglas generales sobre la responsabilidad civil" ya que "la negativa del acreedor a recibir el pago constituye una infracción de su parte que puede ser calificada como acto ilícito” (p. 358). La responsabilidad del acreedor moroso surgiría siempre y cuando el deudor probara los menoscabos sufridos (Wayar, 2000, p. 347; Padilla, 1996, p. 610), y a condición de que concurrieran todos los requisitos de la responsabilidad civil (p. 358).

Padilla (1996) se preguntaba qué solución cabría dar si el deudor hubiera usado la cosa; en este caso, el deudor debería al acreedor un precio por el uso, debiéndose entonces compensar ese precio con los gastos de conservación (p. 611). Por lo que respecta a las eventuales pérdidas por frustración de ganancias, Padilla (1996) negaba su resarcibilidad dado que:

[...] no debe perderse de vista que si el deudor no pudo desobligarse en término para poder concluir otro negocio del que invocaría la pérdida de ganancias, ello no se debió exclusivamente a una conducta del acreedor, ya que en sus manos estaba el pagar por consignación y de tal suerte liberarse de la deuda (p. 611) $)^{13}$.

Al comentar los arts. 1430 y 1431 (CCARG, 1869), la doctrina mencionaba que el derecho del vendedor/deudor dispuesto a pagar frente al comprador/acreedor moroso de cobrarle "los costos de la conservación y las pérdidas e intereses” era, en definitiva, una "mera derivación de las virtualidades de la mora del acreedor" (Llambías y Alterini, s. f., p. 523), sentido que comparten Lagomarsino y Cifuentes (1986, p. 576) y Gregorini Clusellas (1999, p. 626) y, según este, alcanzarían incluso el resarcimiento del daño moral (p. 576).

13 Hay que agregar que, pese a que el cumplimiento por medio de la consignación es una facultad y no un deber, si pudiendo pagar así no lo hubiese hecho, el desmedro patrimonial correría por su cuenta, por aplicación del art. 1111 del ccarg de 1869: "el hecho que no cause daño a la persona que lo sufre, sino por una falta imputable a ella, no impone responsabilidad alguna”. 
La elaboración doctrinaria se había cristalizado en los distintos Proyectos de reforma al derecho privado: todos disciplinaron la cuestión, algunos expresamente, otros por remisión a los efectos de la mora del deudor. Sin embargo, el texto legal vigente no hizo ni una cosa ni la otra.

Pese a ello, la doctrina nacional reconoce ese efecto sin siquiera preguntarse por el fundamento. Para Compagnucci di Caso (2017) la responsabilidad es un efecto y ello no requiere mayores explicaciones (p. 270). Calvo Costa (2015) considera que "los efectos de la mora del acreedor son similares pues, por analogía, a los de la mora del deudor” y también enuncia como primer efecto de la mora del acreedor su responsabilidad "por los daños moratorios sufridos por el deudor ( $v . g r$. Gastos de depósito y guarda de la cosa a entregar por éste)" (p. 793)

Empero, hay autores que ensayan una propuesta interpretativa más articulada. López-Mesa (2015) postula dos efectos diversificados: por un lado, "el acreedor responde por su dolo y por su culpa frente al deudor (ccc, art. 729), factores de atribución que se aprecian conforme con las reglas corrientes del Código"; por otro lado, "si el deudor debiese hacer gastos para conservar la cosa, el acreedor está obligado a satisfacerlos desde la constitución en mora". Sin embargo, advierte que "injustificada no equivale a culposa", de hecho:

[...] toda negativa culposa o dolosa del acreedor a recibir un pago del deudor es injustificada; pero la inversa no es exacta, porque no toda negativa injustificada es culposa. Lo injustificado de la negativa es una característica que se puede apreciar objetivamente y que no depende de evaluaciones de tipo culpabilístico (López-Mesa, 2015, p. 485).

Según Pizarro y Vallespinos (2017), el principio rector en la materia está dirigido a:

[...] evitar al deudor cualquier consecuencia dañosa derivada de la falta de cooperación del acreedor y a mantener, en la medida de lo posible, la integridad de la prestación a la que tiene derecho

14 El mismo fundamento sostienen Pizarro y Vallespinos, (2017, p. 38). También enumera, sin más, y en primerísimo lugar, este efecto de la mora del acreedor Negri (2015, p. 299). el acreedor pese a hallarse en una situación reprobada por el ordenamiento jurídico [...] los efectos de la mora del acreedor no se configuran como una sanción de una obligación del acreedor, sino como una disciplina de las consecuencias económicas de eventos que inciden sobre la prestación debida por el mismo deudor (p. 38).

Ossola (2016) conecta la responsabilidad por daños irrogados al deudor con otro efecto propio y característico de la mora del acreedor, a saber: la "traslación de los riesgos al acreedor"; de hecho, según este autor, "al quedar el acreedor constituido en mora, se produce la traslación de todos los riesgos del incumplimiento obligacional en cabeza del acreedor, lo que se manifiesta de varias maneras" (p. 768), entre otras, precisamente, la atribución de responsabilidad por daños.

En cuanto a la extensión del deber resarcitorio de los daños derivados de la mora creditoris, Alferillo (2016b) subraya que "el acreedor en mora asume los daños que tengan un nexo adecuado de causalidad con su situación obligacional” (p. 340).

En resumen, con distintos matices y fundamentos, hay una posición que la doctrina argentina ha asumido y asume con cierta uniformidad: el acreedor moroso debe reembolsar los gastos y resarcir los demás daños (incluso morales) provocados a causa de su mora.

\section{Algunos modelos legislativos en el derecho comparado}

Nos limitamos a repasar algunos dispositivos legales presentes en las áreas geográficas europea y latinoamericana.

El $\$ 304$ del Código Civil alemán (вGB, 1896) establece que "si el acreedor está en mora, el deudor puede exigir el resarcimiento de los mayores gastos que el mismo ha debido hacer por el ofrecimiento infructuoso, como también por la custodia

15 Similar solución emana del art. 816 del Código Civil portugués (1966): "el acreedor en mora indemnizará al deudor de los mayores gastos que este debe realizar a causa del ofrecimiento infructífero de la prestación y la guarda y conservación del respectivo objeto". 
y conservación del objeto debido"15. A su vez, el $₫$ 381 hace pesar sobre el acreedor los gastos relativos al depósito liberatorio. Señala Cabanillas-Sánchez (1987) que para activar este deber del acreedor, no se requiere culpa pues no se trata de una obligación de daños y perjuicios semejante a la del deudor en caso de incumplimiento (p. 1411). Según Larenz, conforme lo refiere Cabanillas-Sánchez (1987), el deber del acreedor incluiría los gastos de conservación, pero no los daños provocados, por lo que habría que:

[...] tener en cuenta los gastos de almacenaje, primas de seguro, gastos de asistencia y alimentación de ganados; pero no las ganancias dejadas de obtener por el deudor - como, por ejemplo, el arrendamiento de uso que en otro caso hubiese podido concertar de los locales que necesitó para la conservación de las cosas-, ya que éstas son 'daños' (Schaden), pero no 'gastos' (Aufwendung) (p. 1412).

Más amplio es el modelo de solución que emana del Código Civil italiano (1942). En este, el acreedor moroso está obligado a soportar los gastos por la custodia y la conservación de la cosa debida y, además, a resarcir los daños derivados de su mora (art. 1207). Según Morasco (2004), el daño debe ser entendido en el sentido tradicional, es decir, comprensivo tanto del daño emergente como del eventual lucro cesante, y que con relación a este último se exige un estrecho vínculo causal con la falta de liberación del deudor, o con su demora (p. 676). En definitiva, el daño debe ser resarcido según las reglas generales (Visintini, 1986, p. 147).

En Francia, la reciente Réforme du droit des contrats, du régime général et de la preuve des obligations (Ordonnance n. ${ }^{\circ}$ 2016-131 de febrero de 2016) introdujo importantes modificaciones a la figura de la mora del acreedor al ordenamiento jurídico galo $^{16}$. Aquí interesa simplemente resaltar la regla que surge del art. 1345-3: "Los gastos relativos a la

16 El parágrafo que lleva como rúbrica "La mise en demeure du créancier", sucesivo - es importante señalarlo- al tratamiento sobre mora del deudor, introduce cuatro artículos (1345 a 1345-3), que sustituyen los artículos 1257 a 1264 de la redacción originaria del Code Civil. puesta en mora y a la consignación o al secuestro son a cargo del acreedor". El dispositivo es prácticamente una copia (François, 2016) del derogado art. 1260 del Code Civil des français (CCFR, 1804). Por otra parte, si bien la regla es totalmente comprensible, llama la atención que la Reforma de 2016 haya omitido cualquier tipo de referencia a la responsabilidad del acreedor moroso por daños ulteriores. La redacción del artículo parecería sugerir que el deudor solamente puede reclamar los gastos que realizó para consignar.

En cuanto a los proyectos de unificación del derecho de los contratos y las obligaciones en curso en Europa, interesa destacar brevemente algunas reglas del Código Europeo de Contratos, los Principios de Derecho Europeo de los Contratos y el Draft Common Frame of Reference.

El Código Europeo de Contratos (Academia de Iusprivatistas Europeos, s. f.) dedica una sección entera a la mora del acreedor, pero en ninguno de sus artículos menciona expresamente la responsabilidad por daños del acreedor moroso. Con todo, regula en su art. 104 el supuesto de "mora del acreedor que se resuelve en un incumplimiento", calificación esta última no exenta de significativas repercusiones.

En cuanto a los Principios de Derecho Europeo de los Contratos, el texto elaborado por la Comisión de Derecho Europeo de los Contratos (2000), prevé en su art. 7:110 el supuesto de rechazo de la prestación por parte del acreedor, estableciendo dos opciones para el deudor: entregar en depósito a un tercero el bien o venderlo (en ambos casos, en condiciones razonables). En cualquier supuesto, la norma prevé que el deudor tiene derecho al reembolso o a retener de la venta el dinero suficiente para hacer frente a todos los gastos razonablemente asumidos.

La regulación propuesta por el Draft Common Frame of Reference (Group on a European Civil Code y Research Group on EC Private Law [Acquis Group], 2009) en esta materia (III-2:111-III-2:112) no difiere de la contenida en los Principios europeos de Derecho contractual. Empero, hay una norma que impone a ambas partes el deber de cooperación en el ámbito de la relación obligacional: "El deudor y el acreedor están obligados a cooperar recíprocamente en la medida en que ello pueda ser 
razonablemente esperado para el cumplimiento de la obligación del deudor" (art. III.-1:104) ${ }^{17}$.

Con respecto a esta norma, Prosperi (2009) ha evidenciado que:

[...] caso por caso deberá determinarse si el rechazo de la prestación por parte del acreedor es contrario o no a la buena fe, y si, en consecuencia, se debe tutelar solamente el interés del deudor a la liberación coactiva o también su interés a la concreta realización de la relación obligatoria. A salvo, por supuesto, queda el deber de resarcir el daño, del cual el texto del CFR no se ocupa, pero que deriva en modo pacífico de la ilicitud del comportamiento del acreedor (p. 210).

En cuanto a los modelos legislativos latinoamericanos, el art. 1827 del Código Civil chileno (1855) establece que:

[...] si el comprador se constituye en mora al recibir, abonará el alquiler de los almacenes, graneros y vasijas en que se contenga lo vendido, y el vendedor quedará descargado del cuidado ordinario de conservar la cosa, y solo será responsable del dolo o de la culpa grave.

Según Claro Solar (citado por Salinas-Ugarte, 2011, p. 609), este artículo se refiere solamente a los perjuicios consistentes en alquiler de almacenes, graneros, vasijas, pero no dice que deba abonarle perjuicios. Sin embargo, el propio Salinas-Ugarte (2011) considera que el acreedor debe indemnizar los perjuicios sufridos por el deudor (p. 609). También Fueyo-Laneri (2004) señala que la mora del acreedor provoca el deber de reparación de perjuicios en favor del deudor diligente, invocando un curioso fundamento legal. Esto de acuerdo con la disposición general contenida en el art. 1556, que entre las formas de incumplimiento que dan origen a indemnización, se cuenta el "retardo" en el cumplimiento, y el "no haberse cumplido la obligación" (p. 159).

17 Texto original: "The debtor and creditor are obliged to co-operate with each other when and to the extent that this can reasonably be expected for the performance of the debtor's obligation”.
El Código Civil paraguayo de 1987 enumera entre los efectos de la mora del acreedor, el surgimiento del derecho del deudor a que "se le indemnicen los gastos de conservación o guarda, así como los motivados por requerimientos infructuosos" (art. 429). También en esta línea se alinea el Código Civil brasilero de 2002: "la mora del acreedor exime al deudor no doloso de la responsabilidad por la conservación de la cosa y obliga al acreedor a resarcir los gastos realizados para conservarla" (art. 400) $)^{18}$.

Más amplia es la extensión del deber a cargo del acreedor moroso en otros ordenamientos jurídicos nacionales latinoamericanos. El Código Civil boliviano de 1975 establece que el acreedor moroso "debe resarcir los daños provenientes de la mora" y "soporta los gastos de custodia y conservación de la cosa debida" (art. 328). Por último, tanto el Código Civil peruano de 1984 (art. 1339) como el cubano de 1987 (art. 255) establecen expresamente el deber del acreedor moroso de resarcir los daños provocados por su mora.

\section{Algunas observaciones para la construcción de una solución para el derecho argentino}

Antes de entrar en esta parte central de nuestra investigación, es necesario recapitular brevemente las ideas hasta aquí desarrolladas:

a) En materia de mora creditoris, el CCCARG de 2014 se limita a regular sus requisitos y a disciplinar uno de sus efectos: el mecanismo del pago por consignación.

b) A diferencia del CCARG de 1869, el nuevo referente carece de una norma expresa que imponga al acreedor moroso el deber de reembolsar los gastos y resarcir los daños que su rechazo injustificado ha provocado.

c) La doctrina nacional no ha tenido inconvenientes en reconocer la perduración de la existencia de ese deber; en general, sin demasiados

18 Texto original: "a mora do credor subtrai o devedor isento de dolo à responsabilidade pela conservação da coisa, obriga o credor a ressarcir as despesas empregadas em conservá-la”. 
argumentos, los autores se limitan a formular una lacónica remisión a las reglas que disciplinan el deber resarcitorio a cargo del deudor moroso.

d) En el ámbito del derecho comparado, no son pocos los ordenamientos normativos nacionales $y$ supranacionales, europeos y latinoamericanos que expresamente disciplinan ese particular efecto de la mora creditoris, aunque con diversos fundamentos y extensión (solo gastos de conservación, de consignación o, en definitiva, todos los daños).

Esta descripción panorámica obliga a reflexionar sobre el problema en el derecho argentino actual, pues son varias las razones que desaconsejan resolver el problema a la ligera. Ante todo, porque es imprescindible ubicar un fundamento, si no normativo, al menos jurídico ${ }^{19}$. Además, es necesario dar con una solución que sea capaz de articularse en función de las distintas situaciones que puedan verificarse en la praxis.

En términos más claros: si se pretende hacer nacer una obligación a cargo del acreedor moroso, a falta de un fundamento legal expreso, habría que "forzar" su ingreso en algunas de las fuentes de las obligaciones reconocidas por el ordenamiento jurídico argentino; de hecho, "no hay obligación sin causa, es decir, sin que derive de algún hecho idóneo para producirla, de conformidad con el ordenamiento jurídico" (CCCARG, 2014, art. 726).

Veamos, en primer lugar, si es posible considerar que la "causa" puede ubicarse en la "responsabilidad civil" 20 . El art. 1716 identifica las fuentes del "deber de reparar": "violación del deber de no dañar a otro, o el incumplimiento de una obligación" (CCCARG, 2014). Desde el punto de vista

19 Es cierto que, como sostiene Cabanillas-Sánchez (1987), el deber de resarcir los gastos derivados de la conservación y custodia de la cosa debida se explica en la causa de esos gastos, a saber, la conducta imputable al acreedor que no ha facilitado la liberación del deudor, y que ello, en sustancia, se fundamenta en razones de equidad (p. 1412).

20 El cccArg de 2014 califica en términos de "fuente de obligaciones" a la responsabilidad civil; en efecto, el Capítulo 1, relativo a la "responsabilidad civil”, abre el Título V, intitulado “Otras fuentes de las obligaciones” del Libro Tercero que trata sobre los “Derechos personales”. lógico, funciona allí el principio del tercero excluido: cualquier caso de responsabilidad civil deriva del incumplimiento de una obligación o de la violación del deber de no dañar, tertium non datur.

En cuanto a considerar que el acreedor ha incumplido, el punctum dolens de este planteo radica en la dificultad que supone verificar, prima facie, en la posición del acreedor a un "obligado", en el caso, a recibir el pago. En el fondo, este inconveniente parecería debilitar el argumento que remite vía analogía a la mora debitoris para fundar la responsabilidad del acreedor moroso. Como explican Laffaille, Bueres y Mayo (2009), la analogía mora del deudor, mora del acreedor:

[...] acarrea un equívoco sobre la naturaleza de ambos institutos, a los que se considera como si se tratara de un conjunto unitario con facetas diferentes según se trate del deudor o del acreedor. No es así. Para nosotros se trata de dos figuras absolutamente diversas, sea en los presupuestos como en los resultados. Mientras que la mora del acreedor atiende a la tutela del específico interés del deudor, que se manifiesta en su derecho a obtener liberación (art. 505 in fine, Cód. Civil) frente al comportamiento renuente del acreedor, la mora debitoria constituye un aspecto del incumplimiento de las obligaciones (p. 305).

En definitiva, lo que tienen en común es el hecho básico de retardo, pero hay diversos presupuestos y resultados, lo que justifica que el régimen jurídico deba ser distinto, amén de que el concepto sea único (Laffaille, Bueres y Mayo, 2009, p. 305).

Ahora bien, entre otros criterios, el art. 2 del CCCARG de 2014 ordena interpretar la ley teniendo en cuenta "las leyes análogas". Como hemos visto, el ordenamiento actual regula en una única sección la mora, disciplinando ambas figuras: debitoris y creditoris. Esto parecería favorecer la aplicación analógica de las normas que disciplinan los 
efectos de la mora del deudor al supuesto de mora del acreedor ${ }^{21}$.

A nuestro modo de ver, un argumento adicional para zanjar la dificultad de visualizar un verdadero "incumplimiento obligacional" en la actitud "morosa” del acreedor ${ }^{22}$, podría ubicarse en el art. 729 del CCCARG de 2014, que impone tanto al deudor como al acreedor el deber de "obrar con cuidado, previsión y según las exigencias de la buena fe". Desde este punto de vista, la "relación jurídica" ${ }^{23}$ obligacional supondría un conjunto de deberes recíprocos fundados en la buena fe ${ }^{24}$. En efecto, como señala Canaris (2002) en relación con el derecho alemán, la obligación no se agota en el derecho a una prestación, pues a esta se añade una serie de deberes colaterales (Nebenpflichten) (pp. 272-273). Dentro de esta serie entrarían, según Canaris (2002):

21 Según Compagnucci de Caso (2017) la razón de la analogía con la mora del deudor se apoyaría en que "el acreedor tiene el deber jurídico impuesto en el actual art. 731 del cccN, de permitir al deudor liberarse ante el cumplimiento exacto de la obligación; un comportamiento contrario a ese principio permite calificar su conducta como 'culpable”' (p. 269). El art. 731 del cccARg de 2014 regula los efectos de las obligaciones en relación con el deudor y establece que "[e]l cumplimiento exacto de la obligación confiere al deudor el derecho a obtener la liberación y el de rechazar las acciones del acreedor”.

22 En este sentido, ninguna dificultad advierte Perlingieri (1972): "si el acreedor debe cooperar [...] y no lo hace, entonces incumple. De modo tal que la teoría del incumplimiento no puede construirse exclusivamente en relación con el comportamiento del deudor; es oportuno que se tenga presente el deber de cooperación del acreedor, su eventual incumplimiento $\mathrm{y}$, consiguientemente, el resarcimiento del daño por ilícito civil (¡responsabilidad contractual!)” (p. 49; los signos de exclamación son del autor).

23 La expresión, por lo demás, es empleada en la definición normativa de obligación que ofrece el propio texto legal: "La obligación es una relación jurídica en virtud de la cual el acreedor tiene el derecho a exigir del deudor una prestación destinada a satisfacer un interés lícito y, ante el incumplimiento, a obtener forzadamente la satisfacción de dicho interés” (ccCARG, 2014, art. 724).
[...] las así denominadas cargas (Obligenheiten). Es verdad que frente a su inobservancia aquel sobre quien pesa la carga padece un resultado desfavorable $\mathrm{y}$, sin embargo, la otra parte no cuenta con ninguna "pretensión" (Anspruch) para exigir su ejecución $\mathrm{y}$, por ende, no cuenta con ningún "derecho a una prestación”. Por ejemplo el acreedor que no acepte tempestivamente la prestación del deudor $y$, por lo tanto, incurra en mora accipiendi en el sentido del $\$ 293$ BGB, en efecto no cumple con su carga e incurre en las correspondientes desventajas jurídicas: no obstante, según la perspectiva que sigue la doctrina alemana, el acreedor no lesiona ningún derecho de su deudor. Se reconoce que también estas cargas constituyen un elemento esencial de la obligación (pp. 273-274).

Bajo el imperio del Código derogado, Colmo (1921) seguía esta la línea dogmática (citado en Compagnucci de Caso, 1982, p. 994, nt. 14) cuando señalaba que el acreedor tiene la obligación de hacer lo necesario de su parte para contribuir a que el deudor se desobligue cuando este quiere pagarle, en una palabra, tiene la obligación de recibir el pago.

Aplicando estos conceptos al derecho argentino actual, podríamos establecer que, si el acreedor violara las exigencias de la buena fe, ello podría generar consecuencias negativas, especialmente, el deber de resarcir los daños que esa violación hubiere producido. Incumple el deudor que no realiza la prestación, incumple el acreedor que no adecúa su conducta a la buena fe. Sin embargo, no todos los supuestos asociados al problema de la falta de realización de la prestación por razones atribuibles a la esfera del acreedor pueden subsumirse en un supuesto de comportamiento contrario a las exigencias de la buena fe. Es necesario, entonces, buscar argumentos subsidiarios.

24 Desde un punto de vista más estrictamente dogmático, la obligación es esencialmente un vínculo jurídico que se apoya en la idea de cooperación, se funda en la idea de "relaciones recíprocas de ayuda” y cuya necesidad surge de la fides (Schipani, 2015, pp. 289-290). Sobre la naturaleza, alcance y fundamento de este deber de cooperación a cargo del acreedor, véase San Martín (2011). 
Hay que realizar un esfuerzo parejo para ubicar el fundamento del deber resarcitorio del acreedor moroso en su otra fuente posible, es decir, en la "violación del deber de no dañar a otro" (CCCARG, 2014, art. 1716). Una posibilidad es identificar la antijuridicidad requerida "en la omisión que causa un daño" sin justificación (CCCARG, 2014, art. 1717). Con todo, ello obligaría en cualquier caso a tener que satisfacer todos los requisitos necesarios para dar un juicio afirmativo al an de la responsabilidad, a saber: factor de atribución, daño, causalidad.

Un problema especial, con relevancia práctica, se plantearía a raíz de la dificultada de encontrar una solución adecuada a los supuestos de "oferta infructuosa" pero sin rechazo injustificado. El cCCARG de 2014 impone como condición de la mora del acreedor un grado de imputabilidad ${ }^{25}$. El problema se presenta cuando no es posible imputar al acreedor la falta de realización de la prestación, pero es indudable que el fracaso tuvo que ver, de alguna manera u otra, con el acreedor. En estos supuestos: ¿debe resarcir?, ¿con qué fundamento y con qué alcance?

En este sentido, podría aportar cierta utilidad tomar como modelo la solución que presenta el $\$ 304$ del вGB de 1896. En efecto, en caso de que el deudor hubiere realizado un ofrecimiento infructuoso (sin importar la calificación subjetivo de la actitud del acreedor), el deudor podrá exigir un "resarcimiento de los mayores gastos" (Ersatz von Mehraufwendungen) que comporta el cumplimiento tardío, así como también para compensar los gastos de custodia y conservación del objeto debido.

A nuestro modo de ver, en el derecho argentino debería echarse mano a la figura del "empleo útil" (otra de las fuentes de las obligaciones incluidas en el Título V) para resolver este tipo de situaciones. El art. 1791 (CCCARG, 2014) señala que:

25 Sin embargo, Compagnucci de Caso (2017) refiere una discusión doctrinaria sobre la relevancia o no de la "imputabilidad del acreedor" (p. 269) como requisito de configuración de la mora del acreedor: la mayoría de los autores considera que su inactividad, deficiente conducta o desvío de los deberes de colaboración implica culpabilidad; otra parte, en cambio, señala que puede prescindirse de la indagación de culpabilidad.
[...] quien, sin ser gestor de negocios ${ }^{26} \mathrm{ni}$ mandatario, realiza un gasto, en interés total o parcialmente ajeno, tiene derecho a que le sea reembolsado su valor, en cuanto haya resultado de utilidad, aunque después ésta llegue a cesar. El reembolso incluye los intereses, desde la fecha en que el gasto se efectúa.

El empleo útil es fuente de las obligaciones. Esta herramienta permitiría evitar la indagación de los aspectos subjetivos, pues siempre que hubiese habido un gasto por parte del deudor en beneficio del acreedor moroso, este debería soportarlo, sin importar la imputabilidad de la frustración del cumplimiento.

¿Para qué tipo de gastos podría valer esta regla? Para ingresar en la previsión legal debería tratarse de gastos asociados a una utilidad del acreedor, por ejemplo, de custodia y conservación de la cosa debida. Sin embargo, no podrían ser incluidos los gastos relativos a la oferta infructuosa, por ejemplo, si el deudor pretendiera cobrar los gastos de traslado que debió realizar el cumplimiento (frustrado).

Otro fundamento aplicable, pero limitado a los gastos afrontados por el deudor y relativos a la guarda y conservación de la cosa debida, podría identificarse en la regla que deriva del art. 1357 (CCCARG, 2014): "El depósito se presume oneroso. Si se pacta la gratuidad, no se debe remuneración, pero el depositante debe reembolsar al depositario los gastos razonables en que incurra para la custodia y restitución".

Por último, también en relación con los efectivos gastos afrontados por el deudor para mantener posible el cumplimiento tardío de la prestación, podría echarse mano a la teoría del enriquecimiento sin causa, toda vez que el acreedor moroso obtiene una ventaja gracias a los gastos en que ha incurrido el deudor (Cabanilla-Sánchez, 1987, p. 1412). En el derecho argentino, la figura está caracterizada en el art. 1794 (CCCARG, 2014): “Toda

26 Art. 1781 (cccARG, 2014): "Hay gestión de negocios cuando una persona asume oficiosamente la gestión de un negocio ajeno por un motivo razonable, sin intención de hacer una liberalidad y sin estar autorizada ni obligada, convencional o legalmente”. 
persona que sin una causa lícita se enriquezca a expensas de otro, está obligada, en la medida de su beneficio, a resarcir el detrimento patrimonial del empobrecido [...]".

En fin, el rodeo que hemos dado a través de distintas propuestas intenta hacer frente a la necesidad de ubicar un fundamento, rectius, una "causa" a la obligación del acreedor moroso de resarcir los daños. En cualquier caso, esto demuestra que la cuestión tratada en el presente trabajo no puede quedar absorbida bajo el uniforme remedio del "resarcimiento del daño". En el derecho argentino este remedio está configurado por una serie de reglas que, en determinadas circunstancias, difícilmente se acomodan a la situación que se plantea en caso de oferta infructuosa dependiente de la órbita acreedor, pero no necesariamente imputable a este en términos subjetivos. El principio de "reparación plena” consagrado por el art. 1740 (CCCARG, $2014)^{27}$, aún con sus atenuaciones, impide modelar adecuadamente algunas situaciones. No todas las todas las consecuencias negativas pueden cargarse sobre el acreedor moroso.

\section{Conclusiones}

1. El Código argentino vigente no contiene una norma expresa que imponga de manera general el deber resarcitorio al acreedor moroso; tampoco hay una norma sectorial que permita su extensión. Con todo, la doctrina autoral argentina reconoce, con diversos fundamentos, su existencia.

2. La cuestión no puede resolverse a la ligera apelando analógicamente a las reglas que disciplinan la mora debitoris o a la responsabilidad civil que surge de la violación del deber general de no dañar.

27 La reparación del daño debe ser plena. Consiste en la restitución de la situación del damnificado al estado anterior al hecho dañoso, sea por el pago en dinero o en especie. La víctima puede optar por el reintegro específico, excepto que sea parcial o totalmente imposible, excesivamente oneroso o abusivo, en cuyo caso se debe fijar en dinero [...]" (CCCARG, 2014).
3. Estos dos fundamentos pueden utilizarse pero con dos precauciones. La primera tiene que ver con identificar en la violación del deber de actuar según las exigencias de la buena fe, un supuesto afín al "incumplimiento obligacional". La segunda se refiere a la necesidad de considerar que la antijuridicidad exigida como presupuesto de la responsabilidad civil, en específico, "la omisión no justificada que causa un daño", no resulta aplicable a todos los supuestos problemáticos, como por ejemplo en el caso de "oferta infructuosa" por cuestiones propias de la esfera del acreedor, pero no necesariamente reprochables a él.

4. Todo ello exige pensar en argumentos subsidiarios, alternativos o incluso sectoriales para dar justificación al deber de acreedor moroso de acarrear las consecuencias negativas de la falta de realización de la prestación, especialmente en casos de "mora inculpable". Empleo útil, extensión analógica de la regla que obliga al depositante a reembolsar al depositario los gastos razonables en que incurra para la custodia y restitución, y enriquecimiento sin causa.

5. Ha de revisarse la utilización de la expresión "responsabilidad del acreedor moroso" como efecto de la mora del acreedor. El término "responsabilidad" tiene un significado preciso, no siempre adecuado para explicar todas las situaciones que tienen que ver con "frustración de la realización de la prestación por causas propias de la esfera crediticia”. Convendría hablar, en todo caso, del problema de las consecuencias negativas generadas por estos supuestos y el consiguiente deber del acreedor de soportarlas.

\section{Referencias}

Academia de iusprivatistas europeos. (s. f.). Código europeo de contratos. Disponible en: http://www.eurcontrats.eu/acd2/.

Alferillo, P. E. (2016a). Mora del acreedor y pago por consignación. Jurisprudencia Argentina, 2016-II, 939-956. ISSN 0326-1174.

Alferillo, P. E. (2016b). Obligaciones. En A. Sánchez-Herrero (Ed.), Tratado de Derecho civil y comercial (Vol. 2 pp. 325-340). Buenos Aires: Thomson Reuters - La Ley.

Barros, E. (2008). La responsabilidad civil como Derecho privado. Notas sugeridas por la reseña de C. Ro- 
senkrantz. Revista de Estudios Públicos, 112, 309-338. ISSN 0718-3089.

Borda, G. A. y Borda, A. (2012). Manual de Derecho civil: Obligaciones. Buenos Aires: La Ley.

Cabanillas-Sánchez, A. (1987). La mora del acreedor. Anuario de Derecho civil, 4, 1341-1422. ISSN 0210$301 X$.

Calvo Costa, C. A. (2015). Art. 886. En C. A. Calvo Costa (Ed.), Código civil y comercial de la Nación. Concordado, comentado y comparado con los Códigos de Vélez Sarsfield y de Comercio (Vol. 1, pp. 791-793). Buenos Aires: Thomson Reuters - La Ley.

Canaris, C. W. (2002). Il significato di una regolamentazione generale dell'obbligazione e i titoli I e II del secondo libro del BGB. En I Cento anni del Codice civile tedesco in Germania e nella cultura giuridica italiana. Atti del Convegno di Ferrara 26-28 settembre 1996 (pp. 271-298). Padua: Cedam.

Comisión de Derecho europeo de los contratos. (2000). Principios de Derecho europeo de los contratos. Recuperado de: http://campus.usal.es/ derinfo/Material/ LegOblContr/PECL\%20I+II.pdf.

Comisión Honoraria designada por decreto del Poder Ejecutivo Nacional No 685/95. (1998). Proyecto de Código civil argentino de 1998. Disponible en: http://campus. usal.es/ derepriv/refccarg/proyecto/.

Compagnucci de Caso, R. H. (1982) Mora del acreedor. La Ley, 1981-D, 992-1000.

Compagnucci de Caso, R. H. (2017). Artículo 886. En A. J. Bueres (Ed.), Código Civil y Comercial de la Nación y normas complementarias. Análisis doctrinal y jurisprudencial, 3B (pp. 261-270). Buenos Aires: Hammurabi.

François, C. (2016). Présentation des articles 1345 à 13453 du nouveau paragraphe 2 "La mise en demeure du créancier", La réforme du droit des contrats présentée par l'IEJ de Paris 1. Recuperado de: https://iej.univ-paris1.fr/openaccess/reforme-contrats/titre4/chap4/ sect1/ssect3/para2-demeure-creancier/.

Fueyo-Laneri, F. (2004). Cumplimiento e incumplimiento de las obligaciones. Santiago de Chile: Editorial jurídica de Chile.

Gregorini Clusellas, E. L. (1999). Artículos 1430-1431. En A. J Bueres (Dir.) y E. I. Highton, (Coord.), Código civil y normas complementarias. Análisis doctrinario y jurisprudencial, 3C (pp. 626-628). Buenos Aires: Hammurabi.

Laffaille, H., Bueres, A. J. y Mayo J. A. (2009). Derecho civil. Tratado de las obligaciones. Buenos Aires: La Ley.

Lagomarsino, C. A. R. y Cifuentes, S. (1986). Arts. 14301431. En A. C. Belluscio (Ed), Código civil y leyes com- plementarias. Comentado, anotado y concordado (Vol. 6, pp. 576-577). Buenos Aires: Astrea.

Llambías, J. J. y Alternini, A. A. (s. f.). Código civil anotado. Doctrina - Jurisprudencia, III-A. Buenos Aires: Abeledo-Perrot.

Llambías, J. J. y Raffo-Benegas, P. (2012). Tratado de Derecho civil. Obligaciones, I. Buenos Aires: Abeledo Perrot.

López-Mesa, M. J. (2015). Derecho de las obligaciones. Análisis exegético del nuevo Código Civil y Comercial. Montevideo y Buenos Aires: B de F.

López-Mesa, M. J. (2016). El nuevo Código Civil y Comercial y la responsabilidad civil (de intenciones, realidades, concreciones y mitologías). Revista Anales de la Facultad de Ciencias Jurídicas y Sociales. UNLP, 46, 57-73.

Moisset de Espanés, L. (s. f.). Mora del acreedor. Estudio de Derecho comparado (Brasil, Bolivia y otras legislaciones iberoamericanas). Disponible en: http://www. acaderc.org.ar/doctrina/articulos/mora-del-acreedor.-estudio-de-derecho-comparado.

Morasco, P. G. (2004). La mora del creditore. En: M. Franzoni (Ed.). Le obbligazioni, I. Le obbligazioni in generale (1173-1320 C. C.) (pp. 657-685). Turín: Utet.

Negri, N. J. (2015). Mora. En J. C. Rivera y Medina, G. (Eds.), Código civil y comercial de la Nación comentado (Vol. 3, pp. 296-304). Buenos Aires: Thomson Reuters - La Ley.

Ossola, F. A. (2016). Obligaciones. Buenos Aires: Abeledo Perrot.

Padilla, R. A. (1996). Responsabilidad civil por mora. Buenos Aires: Astrea.

Perlingieri, P. (1972). Il fenómeno dell'estinzione nelle obbligazioni. Nápoles: Edizioni Scientifiche Italiane.

Pizarro, R. D. y Vallespinos, C. G. (1999). Instituciones de Derecho privado. Obligaciones, 3. Buenos Aires: Hammurabi.

Pizarro, R. D. y Vallespinos, C. G. (2017). Tratado de obligaciones, III. Santa Fe: Rubinzal-Culzoni.

Prosperi, F. (2009). La cooperazione del creditore all'adempimento del debitore (art. III.- 1:104 CFR). En: Alpa, G., Iudica, G., Perfetti, U. y Zatti, P. (eds.), Il Draft Common Frame of Reference del diritto privato europeo (pp. 191-213). Padua: Cedam.

Salinas-Ugarte, G. (2011). Responsabilidad civil contractual, II. Santiago de Chile: Abeledo Perrot - Thomson Reuters. 
Salvat, R. M. y Galli, E. V. (1952). Tratado de Derecho civil argentino. Obligaciones en general. Buenos Aires: Tipográfica Editora Argentina.

San Martín, L. C. (2011). Sobre la naturaleza jurídica de la 'cooperación' del acreedor al cumplimiento de la obligación. Revista de Derecho Privado. El Externado, 21, 273-325.

Schipani, S. (2015). Obligationes y sistemática. Apuntes sobre el rol ordenador de la categoría. En Schipani, S. El sistema jurídico romanístico y los códigos modernos (pp. 217-290). Lima: Fondo Editorial de la Pontificia Universidad Católica del Perú.

Visintini, G. (1986). Mora del creditore. En P. Recigno (Ed.), Trattato di diritto privato, IX. Obbligazioni e contratti (pp. 132-151). Turín: Utet.

Wayar, E. C. (2000). El pago por consignación y la mora del acreedor. Buenos Aires: Depalma. 